\title{
Nanostructural Evolution and Property of Silicates Doped with $\mathrm{Er}^{+3}$
}

Kirk Hou ${ }^{*}$, Nan Yao ${ }^{*}$, Christopher D. Haines ${ }^{* *}$, Varadh Ranganathan ${ }^{* *}$, Susan B. Halpern ${ }^{* *}$, Bernard H. Kear ${ }^{* *}$, Lisa C. Klein ${ }^{* *}$, George H. Sigel, Jr.*

*Princeton University, Princeton Institute for the Science and Technology of Materials, Princeton, N. 08544, USA

${ }^{* *}$ Rutgers University, Department of Ceramic and Materials Engineering, Piscataway, NJ, USA

The telecommunications industry has taken advantage of $\mathrm{Er}^{+3}$ 's photoluminescence at $1.54 \mu \mathrm{m}$ to develop $\mathrm{Er}^{+3}$ doped optical amplifiers for application in high bandwidth data transmission lines [1]. Development of next generation of optical amplifiers requires enhancement of the width and flatness of the $1.54 \mu \mathrm{m}$ emission peak. Co-doping with $\mathrm{Al}^{+3}$ and $\mathrm{Y}^{+3}$ has been shown to improve these optical properties while increasing $\mathrm{Er}^{+3}$ solubility in a Si or silica host $[2,3]$. We have used HRTEM imaging, Nano-EDXs Analysis, as well as X-ray Diffraction to study the nanostructural evolution of $\mathrm{Er}^{+3}$ doped silicates co-doped with either $\mathrm{Al}^{+3}$ or $\mathrm{Y}^{+3}$.

Amorphous nanopowders (10-20 nm in diameter) with a composition of $\mathrm{SiO}_{2}-18 \mathrm{Al}_{2} \mathrm{O}_{3}-2 \mathrm{Er}_{2} \mathrm{O}_{3}$ (SAE) were synthesized by combustion flame - chemical vapor condensation, while nanopowders of $\mathrm{SiO}_{2}-8 \mathrm{Y}_{2} \mathrm{O}_{3}-2 \mathrm{Er}_{2} \mathrm{O}_{3}$ (SYE) were synthesized by sol gel synthesis [4]. The SAE and SYE samples were then heat treated at $600,800,1000,1200$, and $1400^{\circ} \mathrm{C}$. Upon annealing these far-from equilibrium nanopowders showed an increase in both peak width and intensity of photoluminescence at $\sim 1.54 \mu \mathrm{m}$ (figure 1).

HRTEM analysis of the SAE nanopowders shows the amorphous nature of the nanopowders at $600^{\circ} \mathrm{C}$, and the formation of nanocrystals at $800^{\circ} \mathrm{C}$ (figure $2 \mathrm{a}$ and $2 \mathrm{~b}$ ). With increasing temperature, agglomeration of these nanocrystals results in a crystalline matrix with amorphous nanoinclusions (figure 2c). These results are supported by selected-area electron diffraction patterns (figure $2 \mathrm{a}$ and $2 \mathrm{~b}$ inserts) which show a broad amorphous diffraction rings at $600^{\circ} \mathrm{C}$, with the appearance of crystalline spots at $800^{\circ} \mathrm{C}$.

Nano-Energy Dispersive X-rays analysis of SAE and SYE samples after heat treatment reveal the existence of an amorphous cristobalite phase $\left(\mathrm{SiO}_{2}\right)$ and a crystalline phase consisting of $\mathrm{Si}$, $\mathrm{O}, \mathrm{Er}$, and the codopant. The composition and structure of this phase is determined by further $\mathrm{XRD}$ analysis. For the SYE samples, this crystalline phase has a pyrochlore structure with a composition of $\mathrm{Er}_{\mathrm{x}} \mathrm{Y}_{2-\mathrm{x}} \mathrm{Si}_{2} \mathrm{O}_{7}$. The formation of this solid solution is indicated by the similarity in patterns for $\mathrm{Er}_{2} \mathrm{Si}_{2} \mathrm{O}_{7}$ and $\mathrm{Y}_{2} \mathrm{Si}_{2} \mathrm{O}_{7}$. In an analogous manner, the $\mathrm{SAE}$ system also develops a pyrochlore phase of $\mathrm{Er}_{x} \mathrm{Al}_{2-\mathrm{x}} \mathrm{Si}_{2} \mathrm{O}_{7}$.

Diffusion of $\mathrm{Er}^{+3}$ ions to take up specific lattice locations results in enhanced optical properties of these silicate materials. Noted phase separations are evaluated by comparison with $\mathrm{Y}_{2} \mathrm{O}_{3}-\mathrm{SiO}_{2}$ systems in which equilibrium phases of cristobalite and $\mathrm{Y}_{2} \mathrm{Si}_{2} \mathrm{O}_{7}$ are found. Identical valence and nearly matching ionic radii suggest the formation of a solid solution in which the $\mathrm{Er}^{+3}$ replaces $\mathrm{Y}^{+3}$ ions. 
References

1) Becker, P.C.; Olsson, N.A.; Simpson J.R. Erbium-Doped Fiber Amplifiers Fundamentals and Technology. Harcourt Brace \& Company, London (1999).

2) Zhou, Y.; Lam, Y.L.; Wang, S.S.; Liu, H.L.; Kam, C.H.; Chan. Y.C. Appl. Phys. Lett. (1997), $71,587$.

3) Ting C.; Chen S.; Hsieh W.; Lee H. J. Appl. Phys. (2001), 90, 5564.

4) Haines, C.D.; Ranganathan, V.; Halpern, S.B.; Kear, B.H.; Klein, L.C.; Sigel, G.; Yao, N. Broad, Flat Fluorescence Emissions from Nanostructured Rare-Earth Doped Silicates (Submitted)

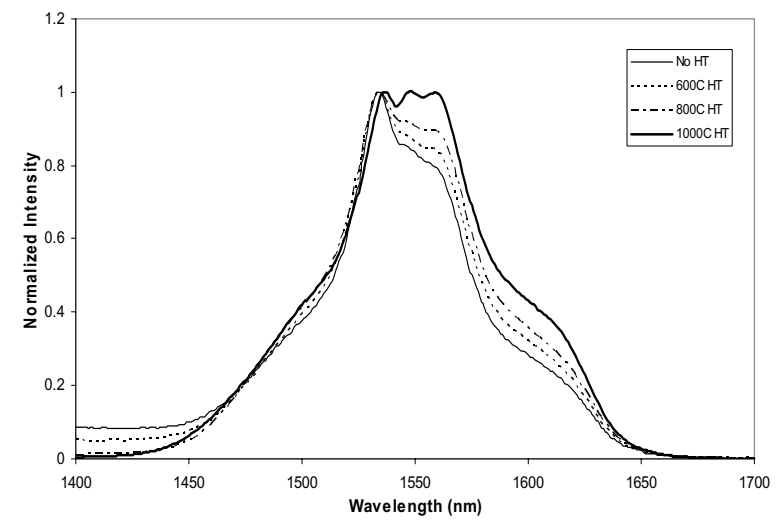

Figure 1a. Photoluminescence Spectra for SAE samples after heat treatment at 600,800 and $1000^{\circ} \mathrm{C}$.

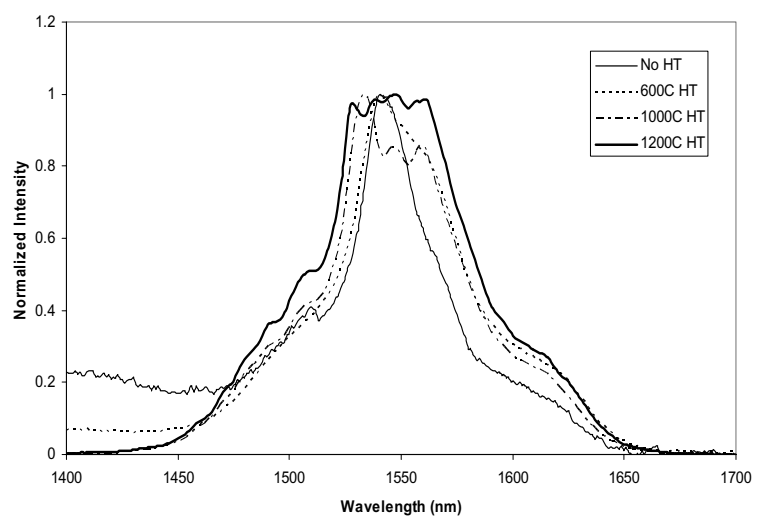

Figure 1b. Photoluminescence Spectra for SYE samples after heat treatment at 600,1000 and $1200^{\circ} \mathrm{C}$.

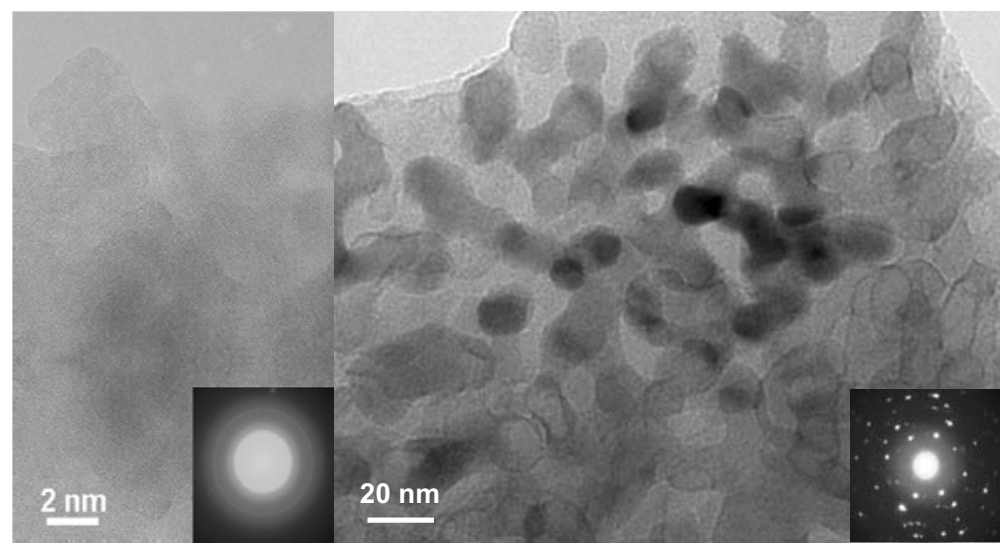

Figure 2a
Figure $2 b$

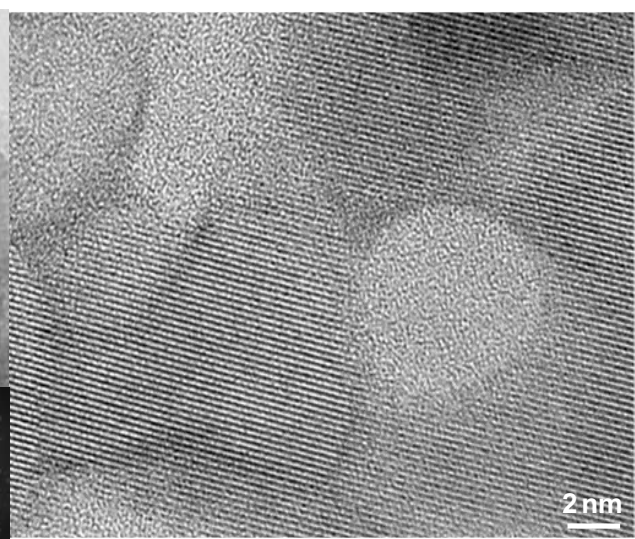

Figure 2c

Fig 2a. Amorphous SAE samples annealed at $800^{\circ} \mathrm{C}$. Fig $2 \mathrm{~b}$. Growth of nanocrystalline phase in SAE samples after heat treatments of $1000^{\circ} \mathrm{C}$. Fig 2c. Amorphous Silica Nanoinclusions in devitrified SAE samples after annealing at $1400^{\circ} \mathrm{C}$. 